\title{
Hydroxylation of Chlorinated and Unchlorinated Chlorophylls in vitro
}

\author{
M. Senge*, A. Struck**, D. Dörnemann*, H. Scheer**, and H. Senger* \\ * Fachbereich Biologie/Botanik. Philipps-Universität. D-3550 Marburg/Lahn. \\ Bundesrepublik Deutschland \\ "*: Botanisches Institut der Universität, Menzinger Straße 67, D-8000 München 19. \\ Bundesrepublik Deutschland \\ Z. Naturforsch. 43c, 515-518 (1988); received March 7. 1988 \\ Chlorophyll Allomerization, Hydroxy-chlorophyll, Thin Layer Chromatography \\ Chlorophyll $a$ is hydroxylated quantitatively in the $13^{2}$-position. when chromatographed on silica \\ gel thin-layer plates. This was shown by using HPLC as a non-destructive method für analyzing \\ photosynthetic pigments. The hydroxy-group of Chl RC I, a 132-hydroxy-20-chloro-chl $a$. described \\ by Dörnemann and Senger (1986) and Scheer et al. (1986), is shown to be artificially introduced \\ during the purification procedure by TLC.
}

\section{Introduction}

During the experiments revealing the structure of an unknown chlorophyll, designated $\mathrm{Chl} \mathrm{RC} \mathrm{I}$, isolated by thin-layer chromatography (TLC) from bulk chlorophylls, a hydroxy-group was detected at the $13^{2}$-position $[1,2]$. It was already discussed whether this hydroxylation took place in vivo or was an artefact, induced during the isolation procedure $[1,2]$. Such an assumption was suggested by divergent results with HPLC separation [3], and by preceeding investigations of chlorophyll alterations on silica gel layers $[4,5]$. The reinvestigation of this question was possible by the application of a non-destructive HPLC method for separation and identification of chlorophylls, together with the use of synthetic pigments.

\section{Materials and Methods}

Chlorophyll $a(\mathrm{Chl} a)$ was prepared from Scenedesmus mutant C-6E and Scenedesmus obliquus WTD 3 and prepurified according to Omata and Murata [6].

20-Chloro-pheophytin $a$ and $13^{2}$-hydroxy-20chloro-pheophytin $a$ were prepared by a modification of the method of Woodward and Skaric [7] from the respective 20-unsubstituted pigments [2]. Metalation with $\mathrm{Mg}$ [8] yielded the respective chlorophylls ( 2 isomers each). The structures were confirmed by NMR and absorption spectroscopy, interconversions and by demetalation to the pheophytins (A. Struck and $\mathrm{H}$. Scheer, to be published).

Reprint requests to Prof. Dr. H. Senger.

Verlag der Zeitschrift für Naturforschung, D-7400 Tübingen 0341-0382/88/0700-0515 \$01.30/0
For enzymatic chlorination, $\mathrm{Chl} a$ was incubated with $\mathrm{KCl}$ and $\mathrm{H}_{2} \mathrm{O}_{2}$ in $\mathrm{KH}_{2} \mathrm{PO}_{4}$-buffer $(0.3 \mathrm{M}$, pH 5.0 ) in the presence of chloroperoxidase (EC 1.11.1.10, Sigma, Munich, C-0278) for $60 \mathrm{~min}$. The reaction products were extracted with diethylether, dried over $\mathrm{MgSO}_{4}$ and subjected to TLC or HPLC analysis.

The pigments were identified by absorption spectroscopy, using an Uvikon 820 (Kontron) spectrophotometer. Molecular weights were determined by plasma desorption mass spectrometry (PDMS) [Senge and Senger in preparation, 9-11].

TLC was performed on Merck silica gel plates (\#5553, Merck, Darmstadt, F.R.G.), according to Dörnemann and Senger [1].

HPLC analysis was carried out using a Spherisorb S5 RP-18 column with $5 \mu \mathrm{m}$ material (250 $\mathrm{mm} \times 4 \mathrm{~mm} \mathrm{ID,} \mathrm{Kontron).} \mathrm{The} \mathrm{elution} \mathrm{system}$ consisted of $\mathrm{CH}_{3} \mathrm{CN} / \mathrm{CH}_{3} \mathrm{OH}(75 / 25 ; \mathrm{v} / \mathrm{v})$ superimposed with a multilinear gradient of water content, starting with $10 \%$ water. The water content was deminished to $0 \%$ within $40 \mathrm{~min}$, follow'ed by a $10 \mathrm{~min}$ phase of regeneration at $0 \%$ water. Finally the water content was increased again up to $10 \%$ within $10 \mathrm{~min}$ [12]. The detection wavelength was $430 \mathrm{~nm}$, the flow rate $1 \mathrm{ml} / \mathrm{min}$.

\section{Results and Discussion}

The reaction product of an enzymatic chlorination of Chl a (comp. I in Fig. 1) was shown to be $13^{2}$ hydroxy-20-chloro-chl $a$ (comp. IV) after purification by TLC [9]. This compound is identical to the Chl RC I described by Dörnemann and Senger [1]. The purified compound IV was eluted in the above 


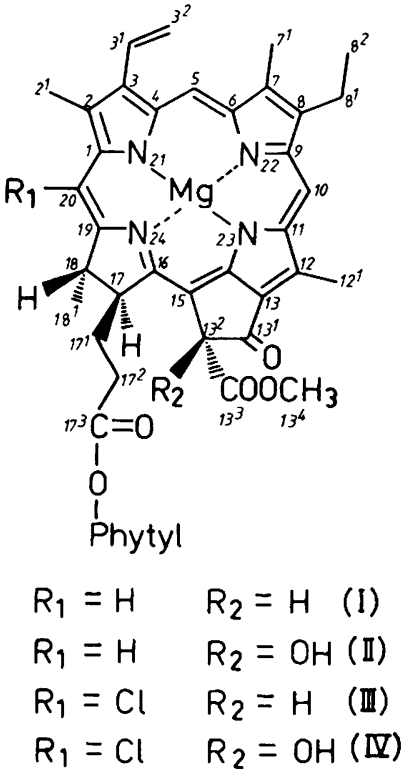

Fig. 1. Structural formula of $\mathrm{Chl} a$ (I), 132-hydroxy-chl $a$ (II), 20-chloro-chl $a$ (III). 132-hydroxy-20-chloro-chl $a$ (IV). All compounds exist as epimers at C $-13^{2}$.

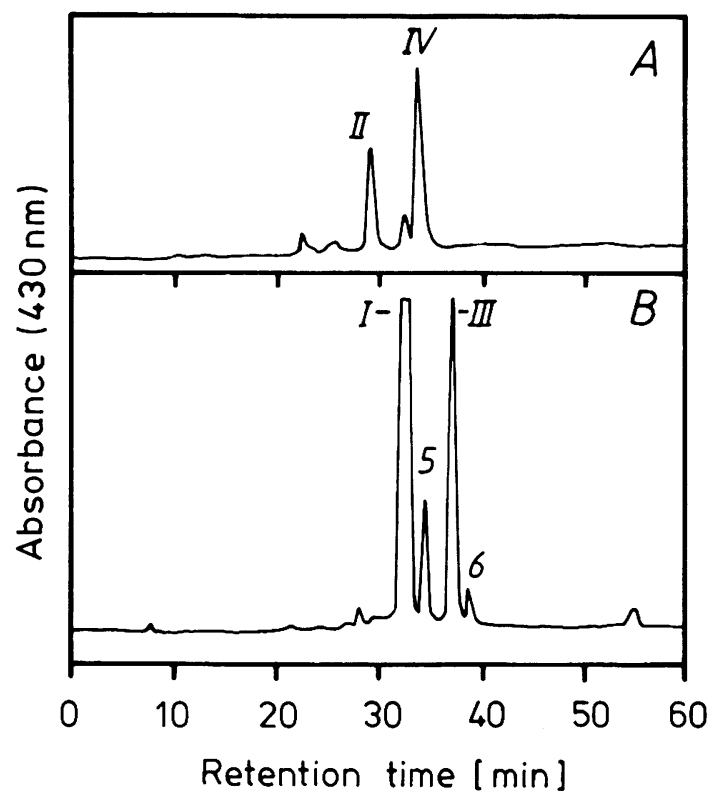

Fig. 2. HPLC elution profiles for the reaction products of an enzymatic chlorination of $13^{2}$-hydroxy-chl (A) and of Chl $a$ (B). I - Chl $a$, II - 132-HO-chl $a$. III - 20-Cl-chl $a$. IV - 13-2-HO-20-Cl-chl $a, 5-\operatorname{chl} a^{\prime}, 6-20-\mathrm{Cl}-\mathrm{chl} a^{\prime}$. described HPLC system after a retention time of $33 \mathrm{~min}$.

In order to circumvent the laborious TLC separation, the reaction products of the enzymatic chlorination of Chl $a$ were extracted from the reaction mixture and directly subjected to HPLC analysis. The elution profile (Fig. 2B) showed major peaks at retention times of 32 and $37 \mathrm{~min}$. Minor peaks derived from epimerization of chlorophylls at C-132. generally occurring in polar solvents and during extraction in chlorophylls containing an enolizable $\beta$-ketoester. By using Chl $a$, purified by HPLC as internal and external standard, the peak at $32 \mathrm{~min}$ was identified as Chl $a$ (I). It showed the typical absorption spectrum with maxima at $661 \mathrm{~nm}$ and $428 \mathrm{~nm}$ in acetone. and PDMS revealed its molecular weight to be 893 (Table I). The compound eluting after $37 \mathrm{~min}$ exhibited absorption maxima at $668 \mathrm{~nm}$ and $432 \mathrm{~nm}$ in acetone. The absorption spectrum was identical to the one obtained for Chl RC I (IV), but while Chl RC I has a molecular weight of 943 [1], this compound gave a $\mathrm{M}^{+}$-peak at $926 \pm 1$ in the PDMS-spectrum. It follows that different products are obtained, when either TLC or HPLC are used for separation of the reaction products of an enzymatic chlorination of Chl $a$.

Similar discrepancies were observed, when $\mathrm{Chl} a$ was purified by HPLC or TLC. When Chl $a$ was analyzed by HPLC before and after being subjected to TLC it showed different retention times. Chl $a$ purified by HPLC was eluted after $32 \mathrm{~min}$, while $\mathrm{Chl}$ $a$ purified by TLC eluted in the HPLC system after 29 min. A spectral analysis showed that both compounds exhibited the same absorption spectrum. with maxima at $661 \mathrm{~nm}$ and $428 \mathrm{~nm}$ in acetone. PDMS confirmed that only the HPLC purified $\mathrm{Chl} a$ had a molecular weight of 893 , in conformity with the

Table I. Absorption maxima in acetone, retention times in HPLC, and plasma desorption mass spectrometry data of Chl $a$ (I), 132-hydroxy-chl $a$ (II), 20-chloro-chl $a$ (III). and $13^{2}$-hydroxy-20-chloro-chl $a$ (IV).

\begin{tabular}{lllll}
\hline Compound & Retention & $\begin{array}{l}\text { Absorption } \\
\text { maxima } \\
{[\mathrm{nm}]}\end{array}$ & $\begin{array}{l}\text { Mass No. } \\
\text { of } \mathrm{M}^{+} \text {-peak }\end{array}$ \\
\hline time [min] & 32 & 661 & 428 & 893 \\
II & 29 & 661 & 428 & 908 \\
III & 37 & 668 & 432 & 927 \\
IV & 33 & 668 & 432 & 943 \\
\hline
\end{tabular}


weight expected from the formula. The Chl $\alpha$ subjected to TLC gave a PDMS-spectrum with the $\mathrm{M}^{+}$peak at 908 mass units. Hence, $\mathrm{Chl} \alpha$ before and after TLC showed the same mass difference of 16 mass units as enzymatically chlorinated $\mathrm{Chl} \alpha$, when purified either by TLC or HPLC.

When Chl $a$, purified by TLC, i.e. the compound eluting at $29 \mathrm{~min}$, was incubated with chloroperoxidase and the extracted reaction products were analyzed by HPLC, an elution profile as given in Fig. $2 \mathrm{~A}$ was obtained. It shows major peaks at 29 min. i.e. not converted starting material and at 33 min. i.e. compound IV.

Since hydroxylation of chlorophyll is a very common allomerization reaction of porphyrins [13-16]. and the mass difference of 16 mass units before and after TLC would be in good accordance with the introduction of a hydroxyl-group, chemically synthesized compounds of known structure were used for comparison. $13^{2}$-hydroxy-20-chloro-chl $a$ (IV) was

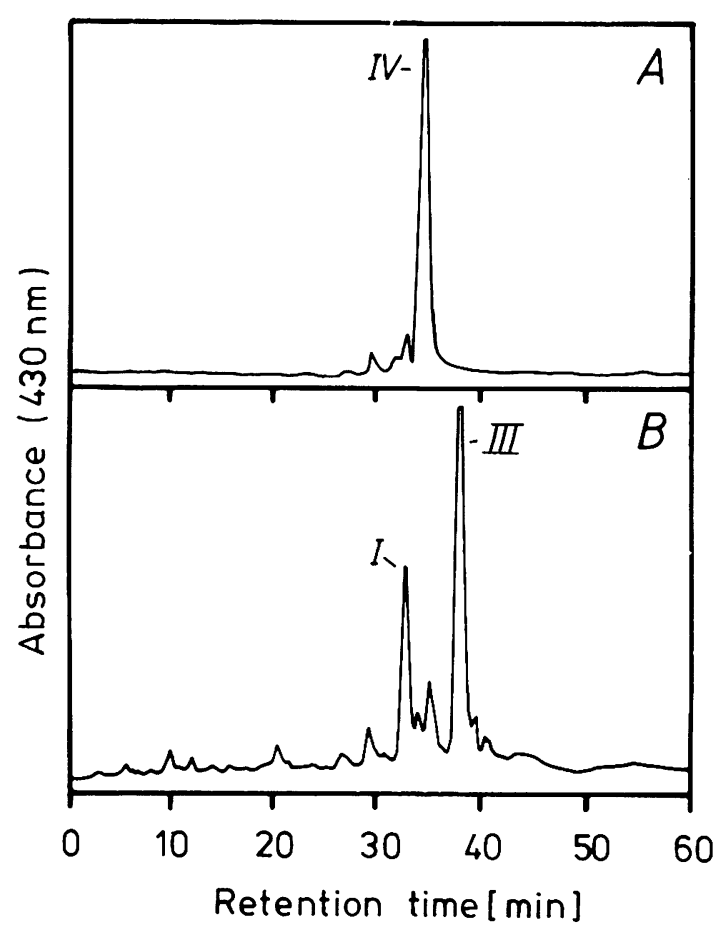

Fig. 3. HPLC elution profiles for the reaction products of a chemical synthesis of $13^{2}$-hydroxy-20-chloro-chl $a$ (A) and a mixture of chl $a$ (I) and 20-chloro-chl $a$ (III) (B). For identification of the peaks see Fig. 2. The epimer mixture of IV is not separated under the conditions of the separation. eluted after a retention time of $33 \mathrm{~min}$ (Fig. 3 A), and 20-chloro-chl $a$ (III) was eluted after $37 \mathrm{~min}$ (Fig. 3B). Hence, the reaction product of the enzymatic chlorination of $\mathrm{Chl} a$ is 20 -chloro-chl $a$ (III) and the hydroxylgroup of $\mathrm{Chl} \mathrm{RC} \mathrm{I}$ is introduced artificially during thin layer chromatography.

Further support for this conclusion was obtained by the following experiments. Pure $\mathrm{Chl} a$ (I) was converted with chloroperoxidase to chlorinated chlorophyll (III) [9], and then subjected to TLC separation. The whole TLC plate was scraped off, and the pigments were extracted exhaustively with acetone. When this sample was analyzed by HPLC an elution profile similar to Fig. $2 \mathrm{~A}$ was obtained (cf. Fig. 5).

The hydroxylation of 20-chloro-chl $a$ (III) to compound (IV) could be followed during separation on the TLC plate. When a sample of the chemically synthesized compounds (III) and (IV) were applied to a TLC plate and developed after the method of Dörnemann and Senger [1], the band of compound (III) migrated initially ahead of the band of compound (IV). During the development the spatial difference between both bands became smaller, and at the end of the TLC procedure the band of compound (III) comigrated with the band of (IV). The compound (IV) deriving from compound (III), was scraped off, extracted and subjected to HPLC analysis. The elution profile is given in Fig. 4. The major peak has a retention time of $33 \mathrm{~min}$, hence compound (III) has been converted to compound (IV) during the TLC procedure.

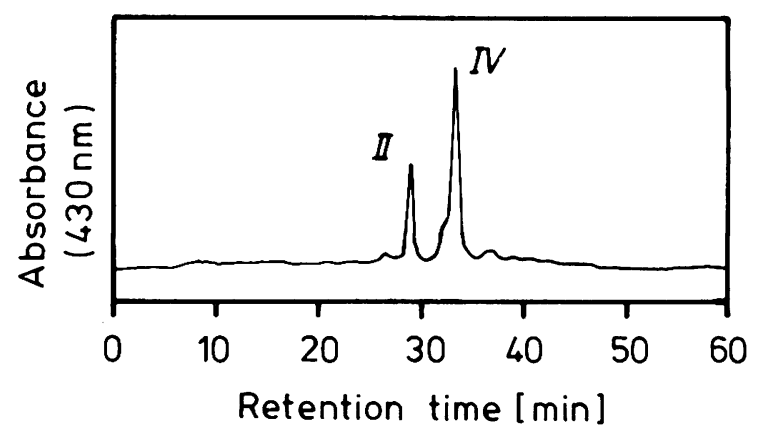

Fig. 4. HPLC elution profile of chemically synthesized 20chloro-chl $a$ (see Fig. 2B) after development on Merck TLC plates. 


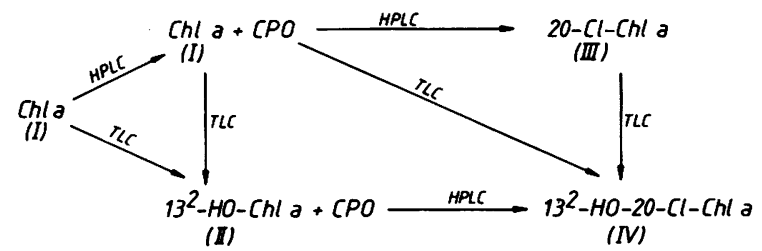

Fig. 5. Scheme of the connections between pure $\mathrm{Chl} a$ and the products obtained in enzymatic chlorination reactions, using either TLC or HPLC for purification of the reaction products. $\mathrm{CPO}=$ chloroperoxidase and cosubstrates, see [9].

The scheme of Fig. 5 summarizes the different experiments. The results clearly demonstrate that hy-

[1] D. Dörnemann and H. Senger, Photochem. Photobiol. 43, 573-581 (1986).

[2] H. Scheer, E. Groß, B. Nitsche. E. Cmiel, S. Schneider, W. Schäfer, H.-M. Schiebel, and H.-R. Schulten, Photochem. Photobiol. 43, 559-571 (1986).

[3] T. Watanabe, M. Kobayashi, M. Nakazato, I. Ikegami, and T. Hiyama, in: Progr. in Photosynth. Res., Vol. I, pp. 491-498 (J. Biggens, ed.), Martinus Nijhoff Publ., Dordrecht 1987.

[4] H. H. Strain, J. Sherma, and M. Grandolfo, Anal. Chem. 39, 926-932 (1967).

[5] M. F. Bacon, Biochem. J. 101, 34C-36C (1966).

[6] T. Omata and N. Murata, Plant Cell Physiol. 24, 1093-1100 (1983).

[7] R. B. Woodward and V. Skaric. J. Am. Chem. Soc. 83, 4676-4677 (1961).

[8] H.-P. Isenring, E. Zass, K. Smith, H. Falk, J.-L. Luisier, and A. Eschenmoser. Helv. Chim. Acta 58, 2357-2367 (1975). droxylation of chlorophylls on silica gel plates is a nearly quantitative reaction. This supports the warning of Strain et al. [4] not to use silica gel materials in chlorophyll chromatography. The results reported here have to be considered during further investigations on the nature of Chl RC I.

\section{Acknowledgements}

The work was supported by grants from the Deutsche Forschungsgemeinschaft to $\mathrm{H}$. Senger and to $\mathrm{H}$. Scheer (Forschergruppe "Pflanzliche Tetrapyrrole"). M.S. was supported by the Studienstiftung des deutschen Volkes.

[9] H. Senger, D. Dörnemann, K. Kotzabasis, M. Senge. W. Schmidt, and M. Wissenbach. in: Progr. in Photosynth. Res., Vol. IV, pp. 491-498 (J. Biggins, ed.), Martinus Nijhoff Publ., Dordrecht 1987.

[10] H. Jungclas. H. Danigel, and H. Schmidt. Org. Mass Spectrom. 17, 86-90 (1982).

[11] R. D. Macfarlane and D. F. Torgerson, Science 191, 920-925 (1976).

[12] K. Humbeck, S. Römer, and H. Senger, submitted to Botanica Acta.

[13] A. Stoll and E. Wiedemann, Fortschr. d. Chem. org. Naturst. I, 159-253 (1938).

[14] P. H. Hynninen and S. Assandri, Acta Chem. Scand. 27, 1478-1486 (1973).

[15] F. C. Pennington, H. H. Strain, W. A. Svec, and J. J. Katz, J. Am. Chem. Soc. 89, 3875-3881 (1967).

[16] P. M. Schaber, J. E. Hunt, R. Fries, and J. J. Katz. J. Chromatogr. 316, 25-41 (1984). 